\title{
CONSTRUÇÃO SOCIOESPACIAL E FORMAÇÃO DO APEGO AO LUGAR DOS INDIVÍDUOS EM SITUAÇÃO DE RUA: O QUE DIZ AS VIVÊNCIAS DESTES?
}

\author{
Brenda Marjory Lopes Correa ${ }^{1}$, Milene Harumi Tomoike ${ }^{2}$ \\ ${ }^{1}$ Acadêmica do Curso de Psicologia no Centro Universitário de Maringá - UNICESUMAR. PIC Sem Bolsa - Unicesumar. \\ brendamlopescorrea@gmail.com \\ 2 Orientadora, Graduada em Psicologia pela UNICESUMAR, Pós-Graduada em Gestão Estratégica pelo Instituto Paranaense de \\ Ensino e Docência em Ensino Superior, Mestre em Gestão pela UNICESUMAR (2017). milene.tomoike@hotmail.com
}

\begin{abstract}
RESUMO
A população de moradores de rua apresenta-se em grande crescimento não apenas no Brasil como em todas as grandes metrópoles mundiais. De acordo com o Observatório Social de Maringá, existiam, em média, 177 mendigos em novembro de 2017 em Maringá. Ao tentar ponderar esta população, este artigo busca captar a construção da estrutura socioespacial concebida por essa população indigente, com atenta observação sobre como ocorre o apego ao espaço e lugar referente aos indivíduos em situação de rua. Foi realizada uma pesquisa de campo, quantitativa descritiva/exploratória, apoiada em embasamentos teóricos, que teve como instrumento de coleta de dados um questionário contendo questões fechadas, que resultou nos dados obtidos convertidos e quantificados em gráficos. Após analisados e embasados em respaldos teóricos, as consequências obtidas pela pesquisam foram, no geral, que a quebra e/ou fragilidade dos vínculos afetivos, principalmente familiares, influenciaram no processo "ir para a rua" dos indivíduos entrevistados. Também foi possível observar que a construção socioespacial, assim como o apego ao lugar do indivíduo em situação de rua, se da principalmente pela identidade que estes indivíduos criaram com o ambiente em que costumam frequentar, sentindo-se parte da relação com o lugar.
\end{abstract}

PALAVRAS-CHAVE: Construção socioespacial; apego ao lugar; indivíduo em situação de rua; identificação.

\section{INTRODUÇÃO}

Os indivíduos, onde quer que estejam, estão inseridos em um espaço ambiental e social. Essa relação entre indivíduo-ambiente-sociedade, basicamente, é o que chamam de ambiente socioespacial, que é estudado pela Psicologia Ambiental, derivado da Psicologia Social (MOSER, 1998). Segundo Elali Pinheiros (2011, p.144), o comportamento socioespacial humano pode ser compreendido enquanto inter-relações do indivíduo, que têm consequências no âmbito sentimental, em relação à situação das pessoas envolvidas e no que se refere ao tipo de interação pretendida/obtida.

Em relação aos indivíduos em situação de rua: "ao mesmo tempo em que os moradores em situação de rua são um evento essencialmente urbano, eles causam, permanentemente, estranhamento e rejeição, como se não pertencessem àquele espaço" (ANDRADE; COSTA; MARQUETTI, 2014, p.3). Ou seja, mesmo sendo histórico e universal o fenômeno de pessoas em situação de rua, a maioria das pessoas tendem a marginalizar essa população.

O indivíduo não deixa de ser influenciado por morar na rua, pelo contrário, ele continua se relacionando e sofrendo intervenções do meio. De acordo com Silva et al. (2014) na medida em que a pessoa é um ser-da-rua, ela absorve esse contexto e é modificada, passando a significá-lo e, a partir dessa significação, passa a modificá-los para uma melhor adaptação de sua existência nesses locais. No âmbito da Psicologia 
Ambiental, este tipo de comportamento se denomina sócio-espacial humano, algo que acontece na inter-relação pessoa/ambiente (ELALI; PINHEIROS, 2011: 144).

Segundo Cavalcante e Nóbrega (2011, p. 184), "a psicologia, ao abordar o sujeito, busca compreender a maneira como ele pensa, categoriza e compreende o espaço e seu conteúdo". Em relação aos aspectos que envolvem a compreensão de "vínculo" ou "apego" com o espaço, é possível declarar que estes são conceitos complexos, com características físico-espaciais do espaço, que tem relação simbólica/afetiva para o indivíduo ou grupo que criou tal relação (ELALI; MEDEIROS, 2011: 53). Ainda, de acordo com Elali e Medeiros (2011, p.53), existem três dimensões que devem ser estudadas para a compreensão do conceito de apego: dimensão funcional, que, segundo Hidalgo e Hernandes (2001), citados por Elali e Medeiros (2011, p. 55), diz respeito ao aspecto físico do espaço que interfere no comportamento do indivíduo que nele se encontra; dimensão simbólica, que tem relação com o conteúdo simbólico de origem sociocultural e individual de cada pessoa, o que influenciará na relação pessoa-ambiente e como o indivíduo ou grupo se comporta mediante cada situação (ELALI; MEDEIROS, 2011: 55); e por fim, a dimensão relacional, que conecta cognitiva e afetivamente pessoas e ambientes, o que colabora na construção da identidade pessoal e comunitária do indivíduo, segundo Hummon (1992), citado por Elali e Medeiros (2011, p. 56).

É de suma importância que as minorias sejam ouvidas, pois, somente assim há possibilidade de evolução. No caso que diz respeito aos moradores de rua, é fundante que estes tenham e sintam realmente que ocupam um lugar de seres humanos, indivíduos capazes, que devem ser ouvidos e merecem apoio. Ao possibilitar que os indivíduos em situação de rua puderam expressar-se pelo menos na esfera de suas construções socioespaciais, e ao analisarr estas construções, abre espaço para que seja aplicada a atenção necessária e colaborativa. Outrossim, seria dada de forma mais clara a compreensão sobre os motivos e consequências de algumas situações no cenário em contexto.

Especificamente em relação à população de rua de Maringá/PR, este projeto buscou:

$\checkmark$ A compreensão de como o grupo em questão se organiza, como a população em situação de rua se relaciona consigo mesmo, uns com os outros e com a sociedade centralizada que mais os descrimina do que os acolhe.

$\checkmark$ Compreender quais os aspectos socioespaciais que configuram a formação do apego ao ambiente desses moradores em situação de rua.

$\checkmark$ Buscou-se, também, perceber se existe algum padrão entre os indivíduos em situação de rua, como, por exemplo, a faixa etária e escolaridade destes, a questão emocional, por exemplo, ao explorar os motivos que os levaram a situação de indigência.

$\checkmark$ Como essa população se sente em relação ao espaço em que ocupa.

\section{MATERIAIS E MÉTODOS}

A pesquisa foi realizada por meio de questionário contendo 21 questões fechadas e uma questão aberta, sendo esta optativa, aplicados no Centro POP de Maringá-PR entre os dias 30/10/2018 e 01/11/2019 nos períodos da manhã, totalizando 8 horas de aplicação. Durante o período de aplicação, circularam na instituição 50 usuários, porém, somente 15 foram voluntários na pesquisa, assim sendo, o universo da pesquisa totalizou 15 respostas. O questionário foi à ferramenta metodológica que orientou a pesquisa, sendo que sua elaboração visou discutir questões a respeito da construção socioespacial e formação do apego ao lugar dos indivíduos em situação de rua e as demais questões que norteiam o tema. 
O questionário com questões fechadas foi escolhido com o objetivo de atingir resultados majoritariamente quantitativos, assim como a questão aberta optativa, que visou buscar informações mais abrangentes em relação ao tema.

\section{$3 \quad$ RESULTADOS E DISCUSSÕES}

Todos os voluntários, até o momento da coleta de dados desta pesquisa, eram indivíduos em situação de rua e usuários do Centro POP de Maringá-PR. Inicialmente, para conhecer o perfil dos voluntários, foram disponibilizadas quatro questões: gênero, data de nascimento, grau de instrução e tempo de permanência em situação de rua. Do total da amostra, $93 \%$ se identificaram como sendo do gênero masculino e $7 \%$ identificaram-se como sendo do gênero feminino. Quanto à faixa etária dos voluntários, $43 \%$ nasceram entre 1990 e 1999 (entre 28 anos e 19 anos), 36\% nasceram entre 1980 e 1989 (entre 38 anos e 29 anos), 14\% nasceram entre 1970 e 1979 (entre 48 anos e 39 anos), $7 \%$ da amostra nasceu em 2000 (com 18 anos). Quanto ao grau de instrução dos voluntários, $46 \%$ possuem o $1^{\circ} \mathrm{grau}$ incompleto, $27 \%$ com $1^{\circ}$ grau completo, $20 \%$ com $2^{\circ}$ grau incompleto e $7 \%$ com $2^{\circ}$ grau completo. Quanto ao tempo de permanência em situação de rua, $40 \%$ relataram estar em situação de rua pó um período de até 6 meses, $27 \%$ relatou estar em situação de rua por um período de 1 à 5 anos, $20 \%$ afirmou estar em situação de rua por um período superior à 5 anos, enquanto $13 \%$ afirmou estar em situação de rua por um período entre 6 meses à 1 ano.

Com base nos resultados obtidos pelo questionário aplicado - método de coleta de dados utilizado (Anexo 1) -, pelo menos $80 \%$ dos entrevistados passaram por uma situação significativa de rompimento de vínculo com o lugar anteriormente à situação de rua (questões 14 e 20 ANEXO 1). É importante ressaltar, no contexto desta pesquisa, que o apego ao lugar, ou seja, a criação de vínculo com o lugar relaciona-se diretamente com o self do indivíduo e as relações deste (ELALI; CAVALCANTE, 2011). Quando há o rompimento deste vínculo, ou a fragilidade dos mesmos, pode-se dizer que o self do sujeito também será afetado. Visto que, segundo Macedo e Silveira (2012), um dos conceitos de "self" em uso nos dias de hoje é o que compreende o termo como aquele que implica a existência de disposições internas e mentais no indivíduo, ou seja, tudo o que o sujeito pensa, incluindo o que pensam sobre si, sobre as relações em que se encontram e, também, sobre o ambiente em que estão inseridos. Assim sendo, é possível afirmar que o que o self do indivíduo interfere diretamente nas perspectivas que o mesmo tem em relação ao futuro, pois, "reagimos a processos e eventos, a mudanças e permanências, em uma escala geral situadas entre segundos e anos" (CAVALCANTE; ELALI, 2011, p.268).

A primeira questão a ser analisada foi a $20^{\underline{a}}$ questão do questionário, e teve como objetivo compreender se haviam vínculos afetivos anteriormente à situação se rua, a questão foi a seguinte: "Anteriormente à situação de rua, qual era a sua maior motivação?", conforme gráfico abaixo (Gráfico 1). 
- Família

Conhecimento
Vida profissional Amigos

nealização pessoal n Sem especificação

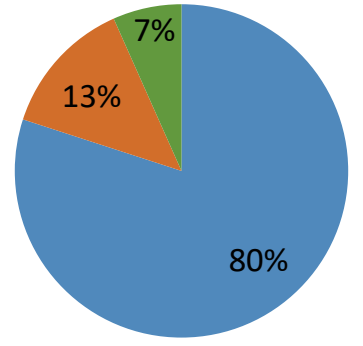

Gráfico 1: Análise dos resultados referente à questão número 20 - Anteriormente à situação de rua, qual era a sua maior motivação?

Fonte: Dados da pesquisa

Segundo o gráfico $1,80 \%$ dos entrevistados, ou seja, a maioria tinha como sua maior motivação a família antes da situação de rua. Seguido por $13 \%$ dos entrevistados que tinham a vida profissional como maior motivação, e por último, apenas $7 \%$ dos entrevistados relataram que não tinham motivação específica anteriormente à situação de rua.

Com base nos resultados obtidos no gráfico 1, é possível constatar que a maior parte dos entrevistados indicaram que, anteriormente a situação de rua, havia algum tipo de conexão de vínculo afetivo familiar, porém, que em algum momento se rompeu. Esta situação é quase unânime entre os indivíduos em situação de rua. Em relação aos indivíduos que se encontram na rua, uma característica comum é: "a falta e/ou fragilidade de vínculos familiares. Essas características levam esta população a ficar sem referência de uma habitação convencional, além de um estado de vulnerabilidade social" (HONÓRIO, 2017, p. 4). O gráfico 7 desta pesquisa demonstra quais as motivações atuais dos indivíduos em situação de rua entrevistados.

As questões número 18 e 19 do questionário visam compreender os tipos de vínculos que são formados no período em que o indivíduo se encontra em situação de rua, essas são respectivamente: "Você sente que faz parte do(s) espaços(s) que costuma frequentar?" e "Você carrega consigo objetos ou animais pelos quais sente apego?", conforme gráfico abaixo (Gráfico 2).

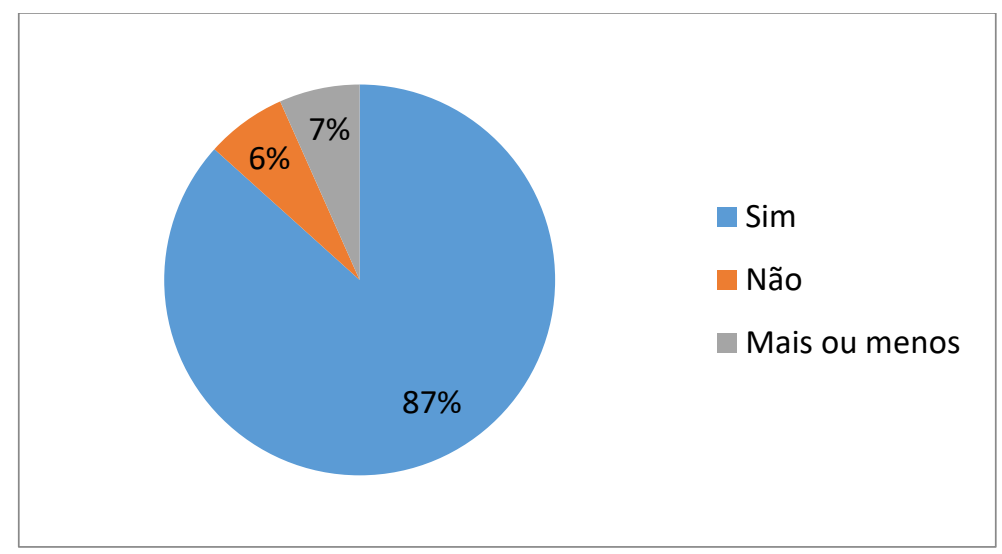


Gráfico 2: Análise dos resultados quanto à questão número 18 do questionário - Você sente que faz parte do(s) espaços(s) que costuma frequentar?

Fonte: Dados da pesquisa

A análise do gráfico 2 constatou que $87 \%$ dos entrevistados sentem que fazem parte dos espaços que costumam frequentar, seguido por $7 \%$ que assinalaram a alternativa "mais ou menos", e apenas 6\% afirmaram que não sentem que fazem parte dos espaços que costumam frequentar. Isto pode ocorrer devido à necessidade da espécie humana de pertencimento social, seja qual for o contexto, que é explicada no artigo "O sentimento de pertencimento social como um direito universal", como pode-se ver na seguinte passagem do texto:

[...] as ideias da Psicologia Sócio-Histórica, que reconhece que a necessidade de pertencimento social é uma condição humana universal, pela qual todos os grupos e indivíduos lutam incessantemente, ao mesmo tempo em que sofrem quando não conseguem essa inserção (TAVARES, 2014, p.2)

Além dos gráficos anteriormente apresentados, outros 8 gráficos surgiram da análise de resultados desta pesquisa com base no questionário em questão aplicado.

\section{CONCLUSÃo}

A partir do estudo realizado e dados coletados, pode-se concluir que o apego ao lugar desenvolvido pelos moradores de rua de Maringá/PR, que são atendidos pelo Centro POP e foram entrevistados, e a construção socioespacial destes se da principalmente pela identidade que estes indivíduos criaram com o ambiente em que costumam frequentar, sentindo-se parte da relação com o lugar. Além disso, foi possível observar que os indivíduos em situação de rua entrevistados, em sua maioria, possuíam vínculos afetivos fragilizados ou rompidos, o que gera necessidade de restabelecimento desses vínculos. Uma das variáveis de controle que poderia ser aplicada e desenvolvida, além da continuação por parte do Centro POP de reconstituir os vínculos afetivos, seria a elaboração de política pública que encaminhasse esses indivíduos à retomada dos estudos, visto que somente $7 \%$ dos entrevistados tinham $02^{\circ}$ grau completo. Ao retomarem os estudos, os indivíduos teriam a possibilidade de, além de se qualificarem, terem a oportunidade de criar elos com a instituição de ensino, colegas de turma, professores e estruturarem representações mais saudáveis, que possibilitariam mais uma abertura para que esses indivíduos se afastassem das ruas.

Uma das possibilidades futuras de pesquisa com o público poderia ser referente à busca mais minuciosa pela subjetividade destes, como se deram os rompimentos e de vínculos afetivos e quais foram os processos pelos quais esses indivíduos passaram até chegarem à situação de rua. Em consequência, buscar compreender possíveis formações de vínculos fora do âmbito da rua, que fortaleçam a criação de identidade desses indivíduos em outros lugares que, ao contrário das ruas, sejam mais estáveis e consistentes, para que esses sujeitos se sintam seguros em todos os sentidos da palavra. 


\section{REFERÊNCIAS}

ALBUQUERQUE, Tatiana Sanson. Geografia da população em situação de rua: mudanças na distribuição espacial na cidade de São Paulo nos anos 2009 - 2014. São Paulo/SP, 2017. Disponível em:

http://anpur.org.br/xviienanpur/principal/publicacoes/XVII.ENANPUR_Anais/ST_Sessoes_Tematicas/ST\%20 8/ST\%208.5/ST\%208.5-05.pdf. Acesso em: 15 dez. 2018.

AZEVEDO DE SOUZA, William. A ASSISTÊNCIA SOCIAL E O TRABALHO COM AS PESSOAS EM SITUAÇÃO DE RUA NO CREAS: : um campo de intercessão.. 2015. 162 f. Dissertação de Mestrado (Mestre em Psicologia.)- Universidade Estadual Paulista - UNESP, [S.I.], 2015. Disponível em: <https://repositorio.unesp.br/bitstream/handle/11449/131844/000851877.pdf;jsessionid=75A6EBFBC6D32C 1D9C8134EF721F38E0?sequence=1>. Acesso em: 15 set. 2018.

CAVALCANTE, Sylvia; A. ELALI, Gleice (Org.). Psicologia Ambiental : Conceitos para a Leitura da Relação Pessoa-Ambiente. 1a. ed. Petrópolis, RJ: Vozes, 2018. 269 p.

CAVALCANTE, Sylvia; A. ELALI, Gleice (Org.). Temas Básicos em Psicologia Ambiental . 1ª̣. ed. Rio de Janeiro: Vozes, 2011. 318 p.

CORBI, Raphael Bottura ; MENEZES-FILHO, Naércio Aquino. Os Determinantes Empíricos da Felicidade no Brasil. São Paulo/SP, 2004. Disponível em: http://www.anpec.org.br/encontro2004/artigos/A04A152.pdf. Acesso em: 2 dez. 2018.

GIL, Antônio Carlos. Métodos e Técnicas de Pesquisa Social . 6ạ. ed. São Paulo, SP: Atlas S.A., 2008. $220 \mathrm{p}$.

GIL, Antônio Carlos. Como Elaborar Projetos de Pesquisa . 4ª. ed. São Paulo, SP: Atlas S.A., 2002. 176 p.

HESKETH , José Luiz ; COSTA, Maria T. P. M. Costa. CONSTRUÇÃo DE UM INSTRUMENTO PARA MEDIDA DE SATISFAÇÃO NO TRABALHO. Rio de Janeiro/RJ, 1980. Disponível em: http://www.scielo.br/pdf/rae/v20n3/v20n3a05. Acesso em: 18 jan. 2019.

HONÓRIO, Luciângela Ramos Orige. FATORES QUE CONTRIBUEM PARA A REINCIDÊNCIA DA POPULAÇÃO EM SITUAÇÃO DE RUA: ESTUdO DE CASO NO CENTRO DE REFERÊNCIA ESPECIALIZADO PARA POPULAÇÃO EM SITUAÇÃO DE RUA (CENTRO POP) NO MUNICÍPIO DE ARARANGUÁ/SC. 2016. Trabalho de conclusão de curso (Pós-graduação em Educação e Direitos Humanos: escola, violências e defesa de direitos) - Universidade do Sul de Santa Catarina, Araranguá/SC, 2016. Disponível em: http://www.uniedu.sed.sc.gov.br/wp-content/uploads/2017/02/Artigo-Luciangela.pdf. Acesso em: 15 dez. 2018.

MACEDO, Lídia Suzana Rocha; SILVEIRA, Amanda da Costa. . In: MACEDO, Lídia Suzana Rocha; SILVEIRA, Amanda da Costa. Self: Um Conceito em Desenvolvimento. Scielo, 2012. Disponível em: http://www.scielo.br/pdf/paideia/v22n52/14.pdf. Acesso em: 15 dez. 2018.

MATSUOKA, Luciane Terumi ; SILVA, Jerson Joaquim da. OS EVENTOS E A HIERARQUIA DAS NECESSIDADES HUMANAS DE MASLOW: CONJECTURAS NA SOCIEDADE CONTEMPORÂNEA. Presidente Prudente/SP, $2013 . \quad$ Disponível em: http://www.unoeste.br/site/enepe/2013/suplementos/area/Humanarum/Psicologia/Os\%20eventos\%20e\%20a \%20Hierarquia\%20das\%20Necessidades\%20Humanas\%20de\%20Maslow\%20conjecturas\%20na\%20socie dade\%20contempor\%C3\%A2nea.pdf. Acesso em: 8 jan. 2019. 


\section{MOSER}

Gabriel. Psicologia

Ambiental.

[S.

I.],

1998.

Disponível

em: http://www.scielo.br/scielo.php?script=sci_arttext\&pid=S1413-294X1998000100008. Acesso em: 25 ago. 2018.

ORIENTAÇÕES TÉCNICAS: CENTRO DE REFERÊNCIA ESPECIALIZADO PARA POPULAÇÃO EM SITUAÇÃO DE RUA - CENTRO POP. Brasília: Gráfica e Editora Brasil LTDA, 2011- . Disponível em: http://www.mds.gov.br/webarquivos/publicacao/assistencia_social/Cadernos/orientacoes_centro_pop.pdf.

Acesso em: 29 nov. 2018.

PADILHA ANDRADE, Luana; LIMA DA COSTA, Samira; MARQUETI, Fernanda Cristina. A rua tem um ímã, acho que é a liberdade: : potência, sofrimento e estratégias de vida entre moradores de rua na cidade de Santos, no litoral do Estado de São Paulo.. 2013. 14 f. Projeto de Pesquisa. (Bacharel em Terapia Ocupacional.)- Universidade Federal de São Paulo., [S.I.], 2013. Disponível em: <http://www.scielo.br/pdf/sausoc/v23n4/0104-1290-sausoc-23-4-1248.pdf>. Acesso em: 08 jul. 2018.

SILVA, Andressa Priscila. Serviço Social no Centro Pop: Relatos dos Usuários. 2017. Trabalho de Conclusão de Curso (Graduação em Serviço Social) - Universidade Federal do Paraná - UFPR, Martinhos, 2017. Disponível em: https://acervodigital.ufpr.br/bitstream/handle/1884/53091/ANDRESSA\%20PRISCILA\%20DA\%20SILVA.pdf? sequence=1. Acesso em: 24 nov. 2018.

SOBRINHO, Afonso Soares de Oliveira. São Paulo e a Ideologia Higienista entre os séculos XIX e XX: a utopia da civilidade. Porto Alegre/RS, 2013. Disponível em: http://www.scielo.br/pdf/soc/v15n32/09.pdf. Acesso em: 31 ago. 2018.

SOARES DE OLIVEIRA SOBRINHO, Afonso. São Paulo e a Ideologia Higienista entre os séculos XIX e XX: : a utopia da civilidade. 2013. 26 f. Artigo elaborado a partir de Dissertação de Mestrado. (Mestre em Políticas Sociais)- Universidade Cruzeiro do Sul - UNICSUL, [S.I.], 2013. Disponível em: <http://www.scielo.br/pdf/soc/v15n32/09.pdf>. Acesso em: 25 ago. 2018.

TAVARES, Rosana Carneiro. 0 sentimento de pertencimento social como um direito universal. $\begin{array}{lcc}\text { Tocantins/TO, } & 2014 . & \text { Disponível } \\ \text { https://periodicos.ufsc.br/index.php/cadernosdepesquisa/article/viewFile/1984- }\end{array}$

8951.2014v15n106p179/pdf_7. Acesso em: 15 dez. 2018.

\section{ANEXO 1}

\section{INSTRUMENTO DE COLETA DE DADOS}

\section{QUESTIONÁRIO}

\section{1 - Gênero do entrevistado:}

1( ) Masculino

2( ) Feminino

02 - Data de nascimento:

1

03 - Grau de instrução: 

1( ) 1 grau incompleto
2( ) 1 grau completo
3( ) $2^{\circ}$ grau incompleto
$4\left(\right.$ ) $2^{\circ}$ grau completo
5( ) Superior incompleto
6( ) Superior completo

04 - Estado civil:

1( )Casado 2( )Solteiro 3( ) União estável 4( )outra

05 - Religião do respondente:

1( )Católica 2( )Evangélica 3( ) Não tem

4( ) outra. Qual?

06 - Você é natural de Maringá?

1( ) Sim 2( )Não. De onde?

06.1 - (Caso não seja de Maringá) - Você pretende continuar em Maringá?

1( ) Sim 2( )Não. 3( ) Talvez

07 - Há quanto tempo você vive na rua? (em Maringá ou não).

$1($ ) até 6 meses 2( ) 6 meses à 1 ano $\quad 3($ ) 1 à 5 anos

4( ) mais de 5 anos

08 - Qual a região de Maringá que você costuma ficar com mais frequencia? Dormir e se alimentar?

Local

e

referência?

Verificar abrangência por UBS.

09 -0 que essa região que você escolheu para ficar mais te agrada?

1( ) Segurança 2( ) As pessoas são receptivas 3( ) Local para se alimentar

4( ) Conforto. 5( ) Conhece bem o ambiente.

6( ) Outros:

10 - Há quanto tempo você frequenta essa região como "principal"?

1( ) 1 mês 2( ) 2 meses 3( ) +3 meses

4( ) -1 mês 5( )Outros: 
11 - Você fez muitos amigos morando na rua?

$\begin{array}{lll}1(\text { ) } \operatorname{Sim} & \text { 2( ) Não } & \text { 3( ) Mais ou menos }\end{array}$

12 - Você se sente acolhido(a) pela população em situação de rua de Maringá?

1( ) Sim 2( ) Não $\quad 3($ ) Mais ou menos

12.1 - Por quê?

13 - 0 Centro de Assistência à População em Situação de Rua de Maringá (CENTRO POP) consegue atender e dar o suporte necessário para você?

1( ) $\operatorname{Sim} \quad 2($ ) Não $\quad 3($ ) Mais ou menos

13.1 - Por quê?

14 - Antes de estar em situação de rua, você residia:

1( ) Com a família - pai, mãe, irmãos etc. $\quad 2($ ) Com cônjuge.

3( ) Sozinho(a).4( )Outro:

15 - Você se considera uma pessoa feliz?

1( ) Sim 2( )Não 3( )Mais ou menos

15.1 - 0 que te deixa feliz?

16 - Qual o período em que você prefere dormir?

1( )Manhã 2( )Tarde 3( ) Noite

4( )Outro:

16.1 - Por quê?

17 - Você busca algum outro tipo de assistência além do CENTRO POP?

1( )Não 2( )Sim 
17.1 (Caso a resposta anterior seja sim) - Onde?

17.2 - Você consegue a assistência necessária nesse(s) lugar(es)?

18 - Você sente que faz parte do(s) espaço(s) que costuma frequentar?

1( )Sim 2( )Não 3( )Mais ou menos

18.1 - (Caso a resposta seja "sim" ou "mais ou menos") - 0 que te faz sentir parte do(s) espaço(s) que costuma frequentar?

19 - Você tem objetos ou animais que carrega consigo? (Que sente apego).

1( ) Sim 2( )Não

19.1 (Caso a resposta seja "sim") - Há quanto tempo?

1( )Menos de um mês 2( )1 a 3 meses

3( )Mais de 3 meses (aproximadamente quanto tempo):

20 - Anteriormente à situação de rua, qual era sua maior motivação?

1( )Família 2( )Vida profissional

3( )Amigos 4( )Conhecimento

5( )Realização pessoal 6( )Sem especificação

7( )Outro:

21 - Atualmente, qual a sua maior motivação?
1( )Família
2( )Vida profissional
3( )Amigos
4( )Conhecimento
5( )Realização pessoal
6( ) Sem especificação
7( ) Outro:

22 - Qual é o tipo de assistência que mais te beneficia e acolhe suas necessidades atualmente?
1( )Atendimento psicológico
2( )Atividades de inclusão social
3( )Assistência de locomoção - intermunicipal e interestadual 
4( ) Alimentação

e necessidades

básicas

banho,

agasalho etc. 5( )Outro:

23. Existe algo que não perguntamos e você acredita ser importante para compreender o que faz você estar morando na rua (em situação de rua)? 